\title{
Investigation of Usage of Passive Solar Energy in Salamis Road's Buildings, Famagusta
}

\author{
Abdolvahid Kahoorzadeh, Sahel Shahwarzi, Elnaz Farjami, and Sina Osivand
}

\begin{abstract}
Sustainable environment and energy systems around architecture world have become major issues of resent decades. This problem has led the architects to deal with solar energy more and more, it is clean and endless. When passive solar energy which is one sort of solar energy would be incorporated into a building, it brings the power of sun (clean energy) for those buildings. Besides, as much as the passive solar energy technologies progress, the quality of energy increases. Hence, it is an interconnection between human and environment.

Passive solar energy exploited through architectural design and different parts of buildings such as positioning windows to enter solar heat and help thermal space. This research tries to show lack of passive solar energy techniques by researching on a series of buildings and their potential parts on Salamis Road, Famagusta, North Cyprus. Finally, this study illustrates in which ways, these buildings can have thermal comfort space as a main objective.
\end{abstract}

Index Terms-Renewable energy, thermal comfort, passive solar energy elements, heating and cooling systems.

\section{INTRODUCTION}

Solar energy is vital for supporting life on earth due to many different factors. First of all, using natural sources like sun prevents global warming. Hence, it is one of the ways ofrespecting to environment. In fact, preventative measures should be taken in order to use fossil fuels which are non-renewable sources of energy and have negative effect on environment.

To achieve an ecological architecture, buildings should be designed environmentally friendly; with enhancing energy efficiency and solar energy precautions we ensure that our construction and action today do not prevent opportunities for future.

The consumption of energy is an important issue in developing countries. Statistics demonstrate that these countries are more dependent to oil, natural gases in comparison to developed countries at the present time. Apart from that, regarding remote, rural areas and Islands is particularly hard to transmit and distribute fossil fuels; it can be expensive and difficult as well. Therefore, producing renewable energy can be the best alternative. When it comes to North Cyprus (TRNC), except solar panels to produce hot water in most of the buildings, there are no preparations to use renewable energy to meet other demands. The power cost is high and people cannot heat and cool their home efficiently. Thus, passive solar energy measures would facilitate life

Manuscript received June 25, 2013; revised September 5, 2013.

The authors are with the Architecture Department, Eastern Mediterranean University, North Cyprus via Mersin 10 Turkey (e-mail: v.kahoorzadeh@gmail.com). conditions in this area as an ecological technology.

Use of passive solar energy elements for buildings can serve as saving energy and create comfortable thermal space for human based on heat index. In Cyprus, because of climate conditions and weakness of construction most of the buildings cannot distribute solar energy in winter and refuse it in summer efficiently; hence, a major problem is buildings was built without applying passive solar energy elements such as thermal mass, thermal insulation, shading devices and appropriate window.

Consequently, this study tries to illustrate in which ways, comfortable thermal space for human can be created by using passive solar energy as ecological architecture strategy. For limitation of field study, the article investigates quality of use of the passive solar energy in Salamis Road between Eastern Mediterranean University and The Wall bar which is one of the most crowded zones in Famagusta, North Cyprus. In addition, because of zone situation, the importance of improvement of living and buildings is much more than other zones in this city. The map below shows field study of this research and yellow line is Salamis Road's demonstrator (See Fig. 1).

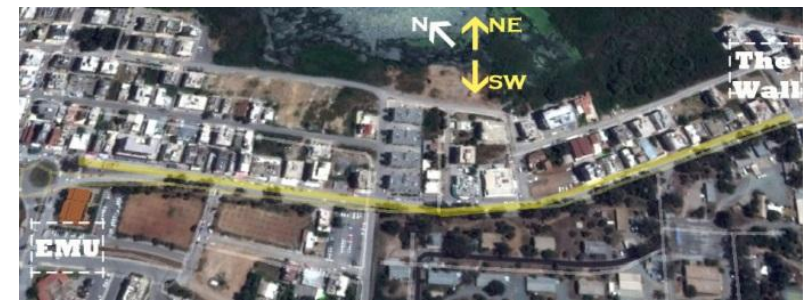

Fig. 1. Field study restriction, Google map, photo taken at 22.04.2012.

\section{LITERATURE REVIEW}

According to a definition at the United Nation conference on environment, in 1994 sustainability is "the ability to meet the needs of present without compromising the needs of future generations." Hence, it happens when there is an integrated connection between environment and human activity. In fact, detailed understanding of site opportunities, microclimate, and orientation of buildings are the basic steps to achieve well-designed buildings in a sustainable way [1].

The passive solar energy is one of the cost-efficient ways to make a building sustainable. This system collects, stores, and uses energy from sun for the entire building without any mechanical or electrical devices. As an architectural design viewpoint, precautions in this respect are large windows on the south facing side of buildings, using heat-absorbent materials such as concrete and stone as heat sinks with appropriate dimensions and thickness [2].

At the next step, human comfort would be provided 
through applying passive solar energy approaches and controlling personal microclimate. The comfort range varies depending on the type of activity, health, cloth, experience and body type. For example, a young or fit man in a specific room may find it more comfortable than an old man. The controlling radiant temperature from the interior surfaces, thermal mass, windows and other parts of a building is also important to ensure the comfort space in both summer and winter [1].

To know how to design a building in every region of the earth, it is indispensable to recognize how sun works in the world.

It is clear that the earth is stationary, and the sun is in motion around the earth. As Fig. 2 illustrates the position of sun above the equator is shown with (+) and below it with (-), on the 20th day of each month. The highest position of sun in the sky for northern hemisphere take place in three months during the summer, then moves quickly through fall towards winter, where it appears in the lowest position for other three months.

For our purpose, understanding sun's position in the sky in any moment is necessary to design passive solar energy techniques. As a matter of fact, this information is significant to locate buildings, interior room arrangements, windows, shading devices and vegetation as well [3].
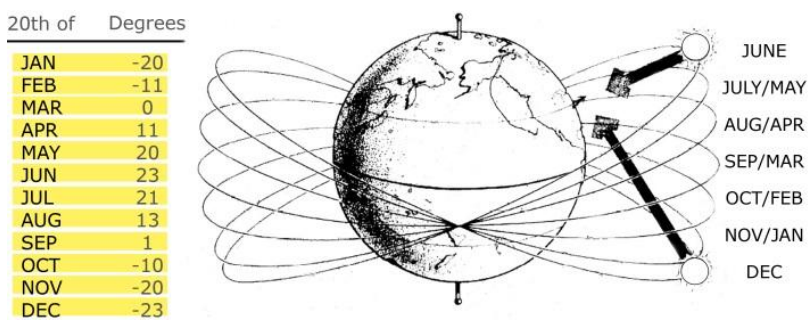

Fig. 2. The sun as it appears from earth on the 20th day of each month [3].

To be more specific, every well-designed building in a passive solar energy way has elements to be considered including window placement and glazing type, shading devices, thermal mass and so on. Meanwhile, following topics are definitions of some of these elements and their role in the framework of passive solar buildings design.

\section{A. Site Location}

The building site and its climate should be evaluated carefully in order to achieve optimum solar design. As a matter of fact, the energy comes from the sun falling onto a surface on the earth during a given time is called "insolation".

At the first step, the survey on site location is hugely depended on insolation as well as local microclimate, such as reverse wind flow, morning fog, etc. Apart from that, undoubtedly, building's orientation is one of the most important factors in order to the passive solar heat gain or loss as a building's architectural features viewpoints. These physical features include roof slope, architectural overhang providing shading, windows area with south facing [4].

On the other hand, the important purpose in this relevant is the existing natural sources in given site especially sun, wind, geothermal heat which is related to passive solar energy should be harnessed for the climatic conditioning of buildings and then should be reflected on the design of their form and also layout. In fact, this is the influence of site situation on the how and where we should use passive energy elements. The different existing or emerging patterns of building development are in a mutual relationship with the following factors:

- Climatic data of zone.

- The rate of exposure of open spaces and the other surfaces.

- The geometry, location, dimensions and volume of surrounding buildings.

- The ability of existing ground as a thermal storage viewpoint.

- Human and mechanical interferences.

- Existing building situation and the architectural heritage [5].

\section{B. Shading Devices}

There are many reasons due to control the amount of sunlight. In fact, the excess solar gain may cause high cooling energy consumption in warm climates. Conversely, sunlight from the south-facing window can contribute to passive solar heating positively in cool climates. Shading devices indeed control daytime overheating and ventilation. Then, little cast of doubt is there shading devices play a key role in passive solar buildings [6].

There are different ways to control solar energy and shading. In general, shading devices are natural landscaping or building elements. Admittedly, it can be provided by a wide range of building components including:

- Horizontal, vertical or egg-crate shading devices in terms of orientation of building's openings

- Landscape features such as trees

- Exterior elements such as overhang

- Glare control devices in indoor space such as venetian blinds.

It is also important to recognize the position of sun in the sky during the different seasons to design operable shading devices [7].

\section{Double Glazing Windows}

Advances in glazing technology have increased these days and the glazing itself can control on the flows of energy between the inside and out. One of the window kinds which have many advantages for saving energy is the double glazing window.

A growing environmental concern and problem are noise pollution, especially in urban regions. A relevant example in this vein is that the noise of 80 decibels caused by outside traffic can cause stress over a continued period of time. Hence, Acoustic glass technologies have been developed to prevent levels of unwanted noise [8].

Generally, the advantages of using double glazing in buildings, which helps to provide a comfortable space in buildings, are:

- Reducing amount of heat lost.

- Financial benefit.

- To manage the environment in a healthy and friendly way.

- There is little difference between the temperature of innermost panel of the glass and room.

- Reducing the amount of outside and unwanted noise [9]. 


\section{DATA Collection MethoD}

Data collection method is chosen from both qualitative and quantitates family of research. Hence, it comes to results with comparative analysis to describe result of evaluation data collection method.

Apart from that, main focus of the data collection method is based on the observation and surveys the existing buildings to acquire knowledge regarding physical environment of the buildings. It was analyzed with statistics based on data collection derived from observation.

Meanwhile, the interviews with architects are considered to assess the professionals' points of view. The results emerges same open-ended questions from three members of Faculty of architecture at Eastern Mediterranean University. Qualitative data, specification of buildings and necessary points regarding research title is acquired through interview. Finally, interview and observation combine together to evaluate ways of heating and cooling buildings.

\section{A. Evaluating Observations}

Building's orientation in the salamis road is based on the street and a long line. Besides, the buildings are very close to each other; it means each building can shelter other buildings. Nevertheless, in some part buildings with longer distance and lower height cannot shadow surroundings. The figure. 3 illustrates the situation of shadowing buildings in terms of location which is calculated with Google sketch up software in specific day and time. In this software the location is defined Famagusta city, with its climatic conditions.

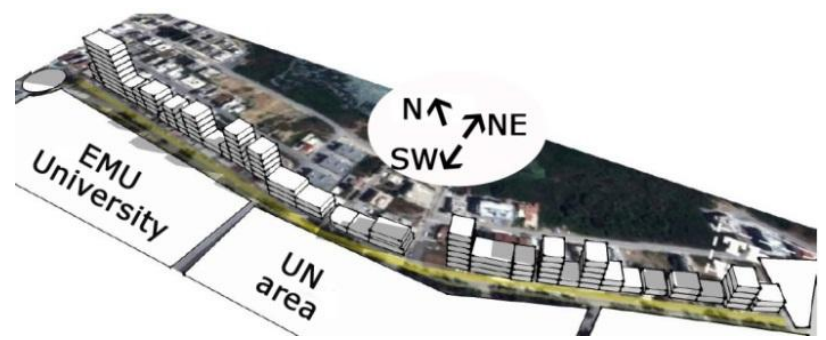

Fig. 3. Situation of buildings on the street and shadowing buildings on each other.

It appears that the dimensions and situation of shadows depend on distance between buildings (d) and their altitude (h) as well (Fig. 4).

Initially, location and orientation are first factors came to investigate in the most passive solar energy research ahead of other detailed techniques. To be more exact, buildings in this zone are orientated from northern west to southern east so as the map below shows, hence the openings on the building's façade are located in a southern west-northern east direction undoubtedly. Apart from that, when it comes to passive solar energy both south and west facings of a building become noticeable more than other sides.

To be more specific, from the south façade buildings can get more solar energy. When the sunlight enters through large south-facing windows, it is clear that a building could take advantage its openings and using the solar energy for heating indoor spaces as a clean and renewable-energy source.

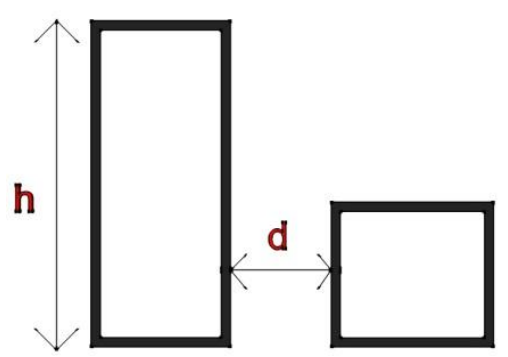

Fig. 4. Dimensions and shadow relations for buildings.

In addition, passive solar buildings require shading devices with appropriate direction and position based on climate and especially orientation as well. For this field study according to orientation, egg-crate shading devices are the most effective one in order to both south and west facades.

Because it prevent to enter sunlight from both west and south direction through windows in summer season in which sun radiates almost with perpendicular angle. On the contrary, in winter, solar energy can heat buildings through the windows directly. Regarding to this issue, horizontal shading devices would also are the second appropriate choices for creating shadows.

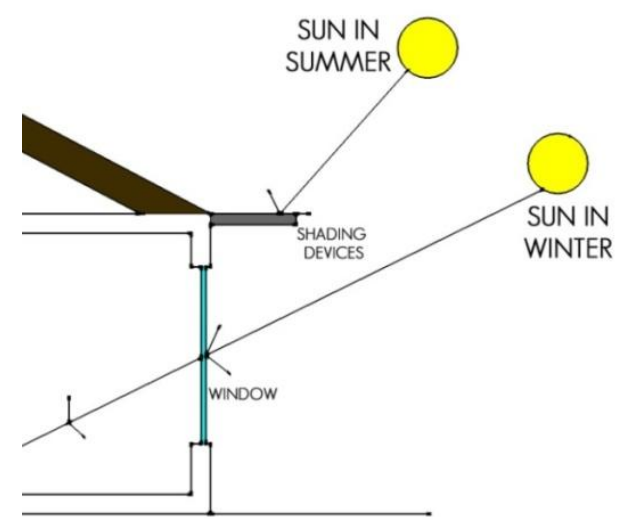

Fig. 5. Overhang of a building or simple shading devices.

Device or overhang can shadow windows and cool these buildings when the sun is in summer position (near to perpendicular angle). On the contrary, in winter position sunlight can enter through windows in order to absorb with thermal mass or heating the buildings. The pictures below are some examples from different types of shading devices in existing buildings (See Fig. 6-Fig. 8).

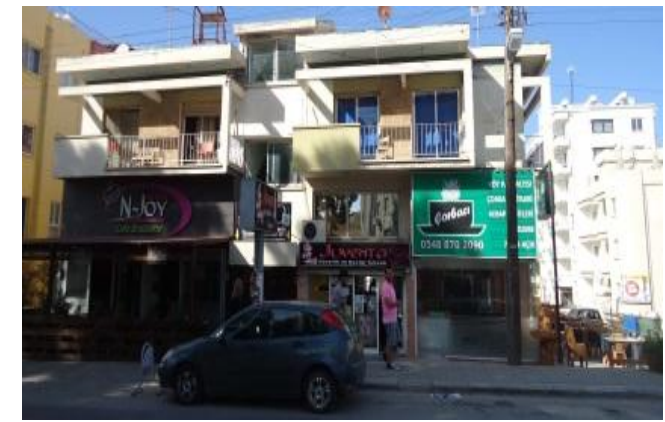

Fig. 6. Example of egg-crate shading devices in buildings of Salamis Road. 


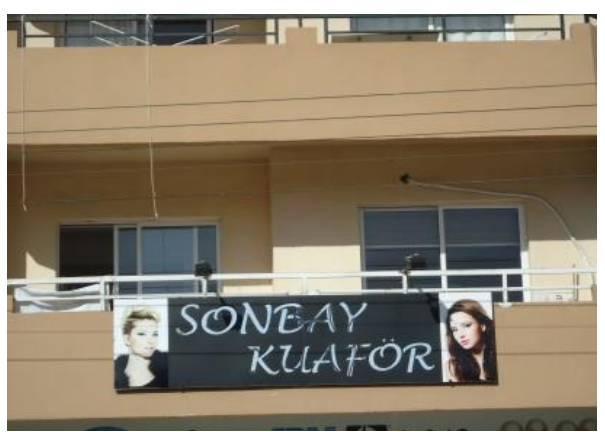

Fig. 7. Example of horizontal shading devices in buildings of Salamis Road.

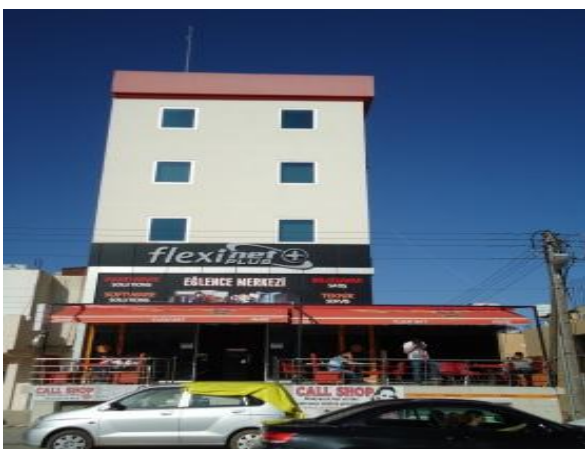

Fig. 8. Example of without shading devices in buildings of Salamis Road.

According to calculations during the observation of the 27 buildings in Salamis Road, percentages statistics show there is no vertical shadow devices or exterior curtain; however, the most percentage took place for horizontal shading devices with $(55.5 \%)$. When it comes to egg-crate just only (18.5\%) occurs unfortunately. Meanwhile $(22.3 \%)$ of buildings do not have shading devices and finally one building with $(3.7 \%)$ solve this problem with natural shading (See Fig. 9).

\section{Kinds of shading devices}
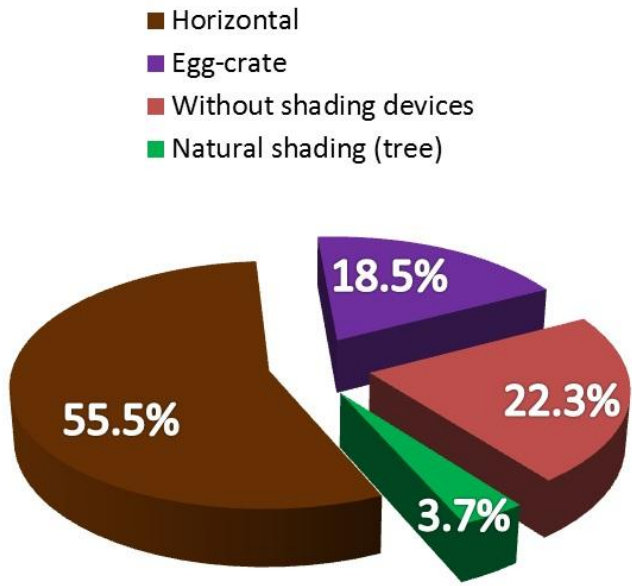

Fig. 9. Using different kinds of shading devices in buildings.

Another technique of passive solar energy that constructors use it for preventing condensation, reducing the amount of heat lost and financial benefit are double glazing windows these days. In this kind of windows, trapped air between two panes acts as insulation. Therefore, a double-glazed window can pass sunlight and prevent losing solar energy in the form of heat in buildings comfortably (See Fig. 10).

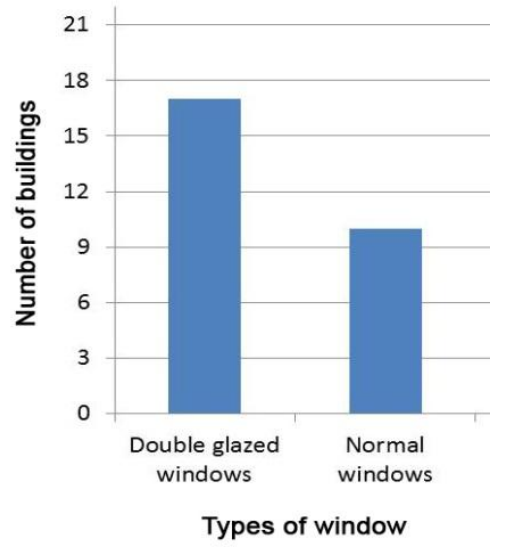

Fig. 10. Number of buildings in terms of type of their windows.

Similarly, with an exact survey in this respect, (37\%) of these buildings do not utilize double glazed window in their facades. Unfortunately, it means 10 buildings out of 27 onecould not reduce the amount of the energy cooling consumption by just using one of the passive solar energy elements.

\section{B. Evaluating Interviews}

During the interview with three architects and specialist in the solar energy field at Eastern Mediterranean University (Prof. Dr. Mesut Özdeniz, Assist. Prof. Dr. Harun Sevinç and Assist. Prof. Dr. Polat Hancer), useful information regarding climatic data and buildings of Salamis Road was obtained. To sum up, comfort zone in ISOPLETH map for Famagusta occurs between $18^{\circ} \mathrm{C}-22.1^{\circ} \mathrm{C}$. Furthermore, air conditioner is required when the temperature is higher than $22.1^{\circ} \mathrm{C}$ which is called overheated temperature or below $18^{\circ} \mathrm{C}$ which is called under heated period. Nevertheless, passive solar elements would have a constructive effect on keeping buildings in appropriate temperature range.

Besides, Famagusta city has a hot-humid climate so that summer is longer than winter. Thermal insulations work effectively when they are located inner side of walls. During the day sunshine will radiate the external wall. If the thermal insulation is on the external layer, the heat enters the wall cannot flow outward, when the temperature falls during the night. Therefore, inside the building become very hot.

It also prevents condensation on the walls. When the buildings have air conditioner, thermal insulations are required for the sake of controlling condensation; otherwise, buildings should be ventilated.

Insulations are used for wall, roof and foundation. However, in some cases, there is no insulation in roofs.

\section{RESULT OF OBSERVATION AND INTERVIEW}

The outcomes of evaluating data are shown as below:

- Effect of orientation of these buildings on thermal comfort is hugely depended on location, for instance, if spaces are faced to west, buildings should provide shading devices.

- Disorder is observed in designing and using all kinds of passive techniques. It means buildings were built in different years with the diverse kind of facilities or architectural knowledge as well.

- If orientation of buildings in Salamis Road is based on the 
street (a long line). The buildings also are very close to each other. Thus, influence of shadow of buildings would be observed on other ones occasionally.

- Larger openings should be placed toward the sun to benefit the maximum solar energy.

\section{CONCLUSION}

This study aimed to contribute solutions and ways to increase comfort index based on analysis field study. After a deep investigation through the buildings, the following precautions can solve the lack of thermal comfort space and make them sustainable via improving passive solar elements:

- When a building is constructed, there is little chance to change entire building, or destroy the identity of building; however, in some part, we may add passive solar elements like shading devices. Additional elements would keep the interior space at a more comfortable and stable temperature. Similarly, the indoor humidity can be controlled.

- Spaces should be organized related to the orientation in order to take the most advantages from natural energy sources. For instance, living rooms could be orientated toward south because dwellers spend their time, mostly there.

- The passive solar energy techniques should be incorporated in a specific building all together to take best results. A building cannot be sustainable with just having insulations.

- Open the building up at night to ventilate and cool interior thermal mass.

- Close the buildings up during the daytime to keep the heat out.

Therefore, with a standard passive solar system, dwellers feel more comfortable in terms of any conditions either cold weather or hot weather. It also has financial benefits. In fact, buildings require relatively small cooling or heating systems.

\section{ACKNOWLEDGMENT}

Authors express the gratitude from Assoc. Prof. Dr. Yonca Hurol and Inst. Nicholas Wilkinson in Eastern Mediterranean University, Department of architecture for their attemps to enhance the academic knowledge. The authors appreciate Prof. Dr. Mesut Özdeniz, Assist. Prof. Dr. Harun Sevinç and Assist. Prof. Dr. Polat Hancer for their useful guidlines in solar energy issues.

\section{REFERENCES}

[1] A. B. David, Passive Solar Architecture: Heating, Cooling, Ventilation Day Lighting, and More Using Natural Flows, The USA: Chelsea Green, 2011.

[2] B. J. Douglas, Passive Solar Buildings, London: The MIT Press, 1992.

[3] E. Mazria, The Passive Solar Energy Book, The USA: Rodale Press, 1979.

[4] T. Galloway, Solar House a Guide for the Solar Designer, Burlington, Canada: Architectural Press, 2004.
[5] T. Herzog, Solar Energy in Architecture and Urban Planning, Berlin: Prestel, 1996.

[6] F. Kreith, Solar Heating and Cooling Active and Passive Design, 2nd edition, The USA: Hemisphere Publishing Corporation, 1982.

[7] D. Prowler. (June 2008). Sun control and shading device [Online]. Available: http://www.wbdg.org/resources/suncontrol.php

[8] K.Robertson. (June 2012). Double glazing for thermal insulation [Online]. Available: http://www.double-glazing-info.com/choosing-your-windows/types-o f-glass

[9] M. Rasey. (May 2012). What is passive solar heating system [Online]. Available: http://www.ehow.com/about_5084758_passive-solar-heating-system. html

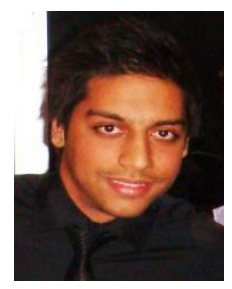

Abdolvahid Kahoorzadeh was born in Bandar-e-Abbas, Iran on September 6, 1986. He go BA. Arch at Azad University, Bandar-e-Abbas, Iran in 2010 and Ms. Arch at Eastern Mediterranean University, Famagusta, North Cyprus in 2013. His major field of study is ecological architecture and solar energy. Besides, he has worked in Tirajeh Gambron Construction Company as an executor of architectural projects for three years. He published" Effect of Solar Gain on Different Glazing Windows and Shading Devices Exemplified in Salamis Road's Buildings, Famagusta, North Cyprus" in ICCE international conference, Canada, 2013. Meantime, his current research interest is Passive Solar Energy. Eng. Arch. Abdolvahid Kahoorzadeh is the Member of Iranian engineers organization.

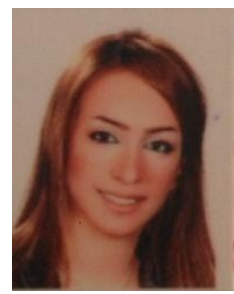

Sahel Shahwarzi was born in Bandar-e-Abbas, Iran on September 6, 1986. She got BA. Arch at PayamNour University, Bandar-e-Abbas, Iran in 2010 and Ms. Arch at Eastern Mediterranean University, Famagusta, North Cyprus in 2013. Her major field of study is climatic issues. Besides, she has worked in Gas Company as a planning designer Meantime, her current research interest is Solar Energy. Eng. Arch. Sahel Shahwarzi is the Member of Iranian engineers organization.

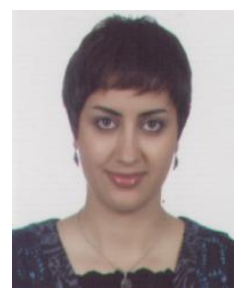

Elnaz Farjami was born in Shiraz, Iran on May 2 , 1989. She got BA. Arch at Apadana Art University in Shiraz, Iran, 2011 and Ms. In. Arch at Eastern Mediterranean University, Famagusta, North Cyprus in 2013. Her major field of study is sustainable architecture and Nano Technology. Besides, she has worked in Architecture Internship in Shiraz Municipality as a designer and BA Internship in the Consulting Engineers Company as a designer. She published "Analyses of Sustainability Lessons from Iranian Traditional Architecture in Museum ofContemporary Art of Tehran" in MIT University, The United States with co-authors: Noushin Hayatdavood, Mahrokh Pooyanmehr, Elnaz Farjami, 2012. Meantime, her current research interest is Nano Furniture. Eng. Arch. Elnaz Farjami.

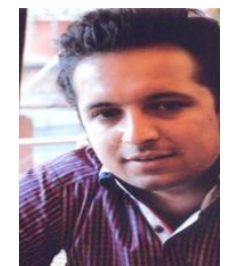

Sina Osivand was born in Ahwaz, Iran on May 15 1987. He got BA. Arch at Azad Universityin Dezful Iran, 2011 and Ms. Arch at Eastern Mediterranean University, Famagusta, North Cyprus in 2013. His major field of study is ecological architecture and solar energy. Besides, he has worked in Naghsh Ara Iraniyan and Sepehr Omran jonob Construction Comany as an executor of architectural projects for five years. Meantime, his current research interest is Passive Solar Energy. Eng. Arch. Sina Osivand. 